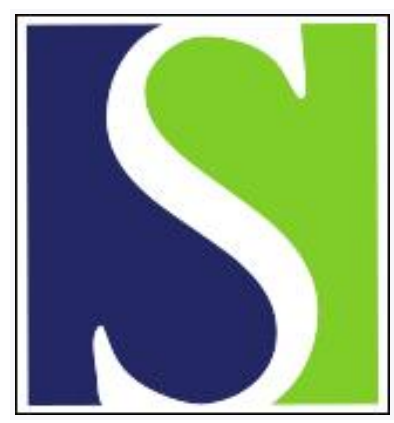

Scand J Work Environ Health 2015;41(5):478-485

https://doi.org/10.5271/sjweh.3517

Published online: 06 Aug 2015, Issue date: 01 Sep 2015

Prevention in dangerous industries: does safety certification prevent tree-faller injuries?

by McLeod CB, Sarkany D, Davies H, Lyons K, Koehoorn M

Safety certification based on the demonstration of safe work practices did not reduce the risk of work injury among experienced manual tree-fallers in British Columbia. While certification may establish a minimum competence, this study establishes the need for additional training or safety controls in order to further reduce the risk of injury in manual-tree fallers.

Affiliation: School of Population and Public Health, University of British Columbia, 2206 East Mall, Vancouver, British Columbia, V6T 1Z3, Canada. chris.mcleod@ubc.ca

Refers to the following texts of the Journal: 2012;38(3):193-208 2003;29(4):288-296

Key terms: certification; dangerous industry; forestry; occupational injury; prevention; program evaluation; safety; safety certification; tree-faller; tree-faller injury

This article in PubMed: www.ncbi.nlm.nih.gov/pubmed/26244646 


\title{
Prevention in dangerous industries: does safety certification prevent tree- faller injuries?
}

\author{
by Christopher McLeod, PhD, ${ }^{1}$ Daniel Sarkany, MSc, ${ }^{2}$ Hugh Davies, PhD, ${ }^{3}$ Kevin Lyons, PhD, ${ }^{4}$ Mieke \\ Koehoorn, $P h D^{5}$
}

\begin{abstract}
McLeod C, Sarkany D, Davies H, Lyons K, Koehoorn M. Prevention in dangerous industries: does safety certification prevent tree-faller injuries? Scand J Work Environ Health. 2015;41(5):478-485. doi:10.5271/sjweh.3517
\end{abstract}

\begin{abstract}
Objectives The aim of this study was to evaluate if safety certification reduces the risk of work injury among experienced manual tree-fallers.
\end{abstract}

Methods This study used a retrospective cohort study design. Experienced manual tree-fallers employed in the Canadian province of British Columbia $(\mathrm{N}=3251)$ between 2003-2008 were enumerated from a mandatory faller registry. Registry records with demographic and certification data were linked to workers' compensation claims for injury outcomes. Data were analyzed using discrete time survival analysis over a two-year period, centered on certification date with pre- and post-certification demarcated into four three-month periods. Models were adjusted for demographic, occupation/industry, previous injury, and seasonal/temporal effects.

Results The relative risk (RR) of work injury during the post certification periods were elevated in comparison to the pre-certification reference period, but the $95 \%$ confidence intervals included "1" for all estimates by the end of follow-up, suggesting no statistically significant increased risk of injury. Results were consistent across different outcome measures of acute injury (ie, fracture or amputations) $(\mathrm{N}=186)$, musculoskeletal injury (ie, back strain) ( $\mathrm{N}=137)$, and serious injury claims (ie, long duration, high cost and/or fatal) $(\mathrm{N}=155)$.

Conclusion Certification did not reduce the risk of work injury among experienced tree-fallers in the province of British Columbia. Non-statistically significant increases in the observed risk of work injury in the months immediately following certification may be attributable to an intervention effect or a methodological limitation related to a lack of individual-level, time-at-risk exposure data.

Key terms forestry; occupational injury; program evaluation.

Manual tree-falling is one of the most dangerous occupations, defined by high injury and fatality rates, within forestry sectors around the world, including Canada (1), Sweden (2), Australia (3), China (4), New Zealand (5) and the United States (6). Many jurisdictions have regulations governing safe-work practices and training for occupations in the forestry sector to mitigate injury risks. Previous research examining the effect of certification and training on injury rates report mixed results $(7,8,9,10)$. The few studies focused on forestry-related certification have shown no effect on aggregate injury rates $(7,8)$. In certification studies in other occupations or industries, the requirement for youth to be trained and certified in the operation of tractors on public roads had no effect on the rate of tractor crashes in the agricultural industry (9) and a commercial driver-licensing program found no effect on traffic accidents (10). A recent systematic review examining the effectiveness of occupational health and safety training and education on behavioral, knowledge and safety outcomes across a

1 School of Population and Public Health, Faculty of Medicine, University of British Columbia, Vancouver BC, Canada.

2 Policy and Regulation Division, WorkSafeBC (Workers' Compensation System of British Columbia), Richmond BC, Canada.

3 School of Population and Public Health, Faculty of Medicine, University of British Columbia, Vancouver BC, Canada.

4 Department of Forest Resources Management, Faculty of Forestry, University of British Columbia, Vancouver BC, Canada.

5 School of Population and Public Health, Faculty of Medicine, University of British Columbia, Vancouver BC, Canada. 
broad range of industries and interventions found that training alone was not sufficient to improve health and safety outcomes (11). However there are few studies that examine the effectiveness of training, certification, or licensure interventions that seek to equip workers in high-risk industries with both the knowledge and the skills of safe-work practices.

In the Canadian province of British Columbia (BC), WorkSafeBC (the Workers Compensation Board of BC) has regulatory authority over the prevention, compensation, treatment and rehabilitation of workplace injuries. In 2003, tree-faller certification was introduced as an optional work requirement for tree-fallers in BC; in 2006, it became a mandatory work requirement. New fallers with $<2$ years of experience are required to participate in classroom and field training (30 days) and have $\geq 180$ days of on-the-job training with a qualified supervisor/ trainer before taking a written and oral examination and a practical skills evaluation for certification. Experienced fallers with $\geq 2$ years of work experience could receive certification without participating in the classroom, field or on-the-job training by taking the written and oral examination testing their knowledge of safe work practices and undergoing a practical skills evaluation.

This study examined if certification reduced the risk of work-related injuries among experienced manual tree-fallers (ie, those who underwent the certification process) in $\mathrm{BC}$ using a retrospective cohort study design. Previous analysis of the hazards and potential errors associated with task of tree-falling has identified both acute injury risk (eg, chainsaw laceration or fractures and concussions due to being struck by falling trees, branches or other debris) and musculoskeletal or strainrelated injury risk (eg, strain injury as a result of a fall due to working on uneven or wet ground) (5). However the injury risks related to manual tree-falling are concentrated among acute injuries and manual tree-fallers tend to have a higher proportion of acute injuries compared to musculoskeletal injuries $(12,13)$. Accordingly, we hypothesized that faller certification focused on safe work practices could reduce all types of injuries (eg, the safe handling of a chainsaw could reduce both acute and musculoskeletal injuries), but that the effectiveness of the certification would be largest for acute injuries.

\section{Methods}

\section{Study sample}

The study sample included all experienced fallers (those with a minimum of $\geq 2$ years of work experience as a faller) employed in the province of BC between 20032008 and registered with the BC Forest Safety Council (the governing body overseeing certification). Fallers aged $\geq 65$ years were excluded. This study sample represented tree-fallers who successfully passed the certification examination and practical skills evaluation during the follow-up period, but who did not participate in the classroom, field, and on-the-job training. The study sample excluded new tree-fallers as a separate intervention group for future evaluation as, at the time of the evaluation, only 31 new fallers had completed certification.

\section{Data source}

The BC Forest Safety Council maintains a registry of tree-fallers in the province. Registry records include tree-faller age, sex, certification date, certification level, work experience and type of falling work. Work injuries were identified from a database of accepted workers' compensation claims maintained by WorkSafeBC (14). Registry records were linked with workers' compensation claim data at the individual level by Population Data $\mathrm{BC}$, the provincial linked administrative data repository, as per procedures adhering to privacy and confidentiality legislation for the use of administrative data for research purposes $(15,16)$.

\section{Study variables}

The main explanatory variable was certification status, using the certification date recorded in the tree-faller registry to define a one-year pre-certification period and a one-year post-certification period for each faller during the study period.

The main outcome of interest was work injury, defined by an accepted workers' compensation claim for short-term disability (ie, time loss), long-term disability (ie, permanent disability) or a fatality with an injury date between 2003-2008. Healthcare-only claims were excluded from the analysis as occupation was not available for these claims. Claims due to occupational diseases such as asthma, cancer or hearing loss, or nontree-falling incidents, such as motor-vehicle accidents, were excluded as these were not directly targeted for prevention by the faller certification program.

Included injuries were further categorized as acute, musculoskeletal, or serious injuries to investigate if the effect of certification differed by type of injury. Using standardized nature of injury codes (17), acute injuries were defined as amputations, fractures, dislocations, concussions, cold or heat exposures, burns, abrasions/ contusions/lacerations or hernias. Musculoskeletal injuries were defined as strains and sprains of the back, upper limb, or lower limb, including carpal tunnel syndrome, bursitis, tendinitis, or tenosynovitis. Serious injuries are defined by the workers' compensation system (18) as fatal claims, or an accepted claim with 
$\geq 1$ of the following: (i) long duration (28 days of wage loss); (ii) high claim costs (equivalent to 28 days of wage loss); (iii) serious medical diagnosis [as defined by ICD 9 codes (16)].

\section{Confounding variables}

Model estimates of the effect of certification on work injury risk were adjusted for the potential confounding effects of demographics and occupation and industry variables, as well as previous claim status. Fixed variables included faller age at time of certification (defined using 10-year groupings of 15-24, 25-34, 35-44, 45-54, 55-64 years), occupation category (defined as forest harvester or non-forest harvester (eg, fire suppressors, arborists), forest region of employment (three regions defined as coastal, northern, and southern interior region representing different terrain, climate and tree harvesting conditions), years of work experience (defined as $1-2,3-5,6-10,11-20$ or $\geq 21$ years), and certification level $[1-5$ and $\mathrm{A}-\mathrm{C}$; the numeric component refers to the tree diameter where 1 is the smallest ( $\leq 20$ inches) and 5 is the greatest ( $>60$ inches), and the alphabetic component refers to the slope of the terrain where $\mathrm{A}$ is the least $(<30 \%$ grade) and $\mathrm{C}$ is the steepest $(>60 \%$ grade)]. Industry unemployment rates, derived from monthly Statistics Canada Labor Force Survey data for primary resource industries (forestry, mining and oil and gas) were included to control for the variability of economic activity in the forestry sector during the follow-up periods. The unemployment rate variable was derived from the average of the mean monthly unemployment rate in $\mathrm{BC}$ for the primary resource sector using Statistics Canada Labor Force Survey and categorized into quartiles based on the distribution during the study period $(0.0-5.9,6.0-8.9,9.0-11.9, \geq 12 \%)$. Previous claim history (yes versus no) was defined by the presence of a previous workers' compensation claim in the two years prior to the 'at risk' time period. Gender was not included as confounding variables as there were too few women in the faller registry.

\section{Analysis plan}

To investigate the effect of certification on work injury risk among tree-fallers, the data was analyzed using discrete time survival analysis and complementary log$\log$ regression $(19,20)$. A discrete time-survival model provided flexibility in defining an intervention (certification) that took place on different dates for each faller and enabled the derivation of a comparable risk estimate before and after certification, controlling for potential confounding characteristics.

Using each faller's individual certification date as a common point in time, a 2-year window of survival analysis was available for each faller, with one year of data before and after the certification date. The study period was restricted one year prior to certification and one year after certification because of limited information on employment status beyond the certification date in the faller registry. Risk of injury was accessed by discrete 3-month periods in the pre-certification year [defined as period 1 (earliest) through 4 (immediately pre-cert)] and in the post certification year [defined as period 5 (immediately post-cert) through 8 (latest)] to control for seasonal and temporal effects (see figure 1). Only the first injury per discrete period was counted, as multiple claims in a 3-month period were rare. The risk of injury [relative risk (RR) with $95 \%$ confidence intervals $(95 \% \mathrm{CI})$ ] was calculated for each 3 -month period relative to period 1. For example, if a faller was certified in February 2007, period 1 included February, March, and April 2006, and period 5 (first-post certification period) included February, March, and April 2007. This approach assumed a uniform work time-at-risk for each faller over the 2-year study period.

Tree-fallers were censored from discrete periods if they were disabled from work for all or most of the period, based on disability status derived from workers' compensation claim data. Fallers were also censored from follow-up following a fatal claim or if they withdrew from the occupation as indicated in the tree-faller registry. All statistical analyses were performed using Stata release 12.0 (StataCorp LP, College Station, TX, USA).

\section{Ethics}

The Behavioral Research Ethics Board of the University of BC (certificate\# H09-02725), approved the study protocol and procedures, which are governed by data agreements between the researchers and the data stewards for the use of the data for research purposes.

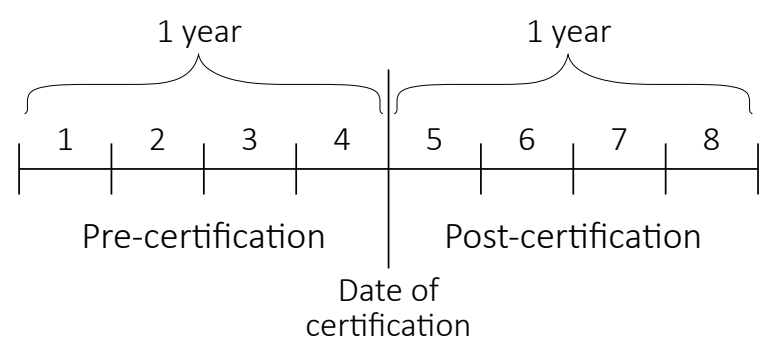

Figure 1. Time windows for survival analysis (3-month periods), 1-year pre-certification and 1-year post-certification- 


\section{Results}

\section{Description of study sample of experienced tree-fallers}

The registry provided data on 3722 tree-fallers for the period 2003-2008. A total of 36 new fallers $(<1 \%)$ were excluded as ineligible and 399 experienced fallers $(10.7 \%)$ were excluded because they could not be found in the linkage-coordinating file used by Population Data $\mathrm{BC}$ to link registry records to workers' compensation claims (ie, were likely not $\mathrm{BC}$ residents but were working in the province). An additional 34 fallers were excluded as over the age of 65 years and another two for a data error in the injury date $(<1 \%)$. The final analytic sample included 3251 experienced tree-fallers ( $87.3 \%$ of the faller registry). Of these, the age at time of certification ranged from 19-64 years with a mean of 42.2 years and standard deviation of 9.7 (table 1). Years of tree-falling experience ranged from 1-50 years, with the majority reporting $11-20$ years $(25.9 \%)$ or $\geq 21$ years of work experience $(22.2 \%)$. Most tree-fallers were engaged in forest harvesting (83.8\%) in the coast $(44.9 \%)$ or southern $(35.0 \%)$ forest region. Most treefallers were certified at grade level $1(44.0 \%)$ and very few at grade level 5 (3.4\%).

The total number of injuries experienced during the study period was 323 ; of these 186 were acute, 137 were strain, and 155 were serious injuries. The number of injuries experienced pre- and post-certification were 130 and 193 , respectively.

\section{Certification and risk of work injury}

Among experienced tree-fallers, results from the adjusted survival analysis ranged from a moderate decrease to no change in RR of a work injury, across all injury types, in the three periods leading up to certification compared to the reference period, and an increase in RR of injury, across all injury types, in the four periods after certification compared to the reference pre-certification period (table 3 ). With a few exceptions noted below, the $95 \% \mathrm{CI}$ for almost all estimates across discrete periods included "1", as well as the estimate from other follow-up periods, suggesting no statistically significant difference in risk of injury to the precertification reference period or across study periods respectively.

Two additional observations for the risk of work injury were noted. First, the period immediately preceding a faller's certification date (period 4) experienced a non-statistically significant decrease in the RR of work injury compared to period 1 for all injury types (table 2). Second, in the period immediately following a faller's certification date (period 5), there was an increase in the RR of work injury compared to the reference period that
Table 1. Characteristics of the manual tree-faller cohort.

\begin{tabular}{|c|c|c|}
\hline & Frequency (N) & $\%$ \\
\hline Total manual tree-fallers & 3251 & 100.0 \\
\hline \multicolumn{3}{|l|}{ Age group (years) } \\
\hline $15-24$ & 101 & 3.1 \\
\hline $25-34$ & 669 & 20.6 \\
\hline $35-44$ & 1075 & 33.1 \\
\hline $45-54$ & 1048 & 32.2 \\
\hline $55-64$ & 358 & 11.0 \\
\hline \multicolumn{3}{|l|}{ Forest region } \\
\hline Coastal & 1461 & 44.9 \\
\hline South & 1138 & 35.0 \\
\hline North & 651 & 20.0 \\
\hline Missing & 1 & 0.1 \\
\hline \multicolumn{3}{|c|}{ Tree-falling occupation type } \\
\hline Production & 2725 & 83.8 \\
\hline Non-production a & 256 & 7.9 \\
\hline Missing & 270 & 8.3 \\
\hline \multicolumn{3}{|c|}{ Tree-falling work experience (years) } \\
\hline $1-2$ & 224 & 6.9 \\
\hline $3-5$ & 563 & 17.3 \\
\hline $6-10$ & 641 & 19.7 \\
\hline $11-20$ & 841 & 25.9 \\
\hline$\geq 21$ & 721 & 22.2 \\
\hline Missing & 261 & 8.0 \\
\hline \multicolumn{3}{|l|}{ Certificate grade level $\mathrm{b}$} \\
\hline 1 & 1431 & 44.0 \\
\hline 2 & 891 & 27.4 \\
\hline 3 & 404 & 12.4 \\
\hline 4 & 413 & 12.7 \\
\hline 5 & 109 & 3.4 \\
\hline Missing & 3 & 0.1 \\
\hline \multicolumn{3}{|l|}{ Year certified } \\
\hline 2003 & 71 & 2.2 \\
\hline 2004 & 1054 & 32.4 \\
\hline 2005 & 1349 & 41.5 \\
\hline $2006^{c}$ & 571 & 17.6 \\
\hline 2007 & 153 & 4.7 \\
\hline 2008 & 53 & 1.6 \\
\hline \multicolumn{3}{|l|}{ Certification period 3} \\
\hline Optional & 2939 & 90.4 \\
\hline
\end{tabular}

a Spacers, forest fire fighters, arborists, seismic line cutters and "other" fallers.

${ }^{b}$ Fallers are certified according to tree diameter (Levels 1-5) and terrain (grade A-C) abilities. These were collapsed to level only given the high correlation between level and grade.

c In 2006, certification became a mandatory work requirement to work as a tree faller in British Coumbia.

remained during the post-certification periods

When considering the effect of the confounding variables presented in table 3 the following observations can be made. Younger workers were at higher work injury risk, as were tree-fallers working in the coastal region, those with a previous claim, and those with a higher certification level (representing working with larger trees and on steeper terrain). Faller type (production versus non-production), work experience, and industry unemployment rate were not statistically significant predictors of injury risk. 


\section{Discussion}

In summary, the risk of work injury among experienced tree-fallers in $\mathrm{BC}$, regardless of type of injury, was elevated in the post-certification period, but all $95 \%$ CI included " 1 " by the end of follow-up suggesting no statistically significant difference in risk compared to the pre-certification reference period. Previous research examining the effect of certification and training on injury rates have reported similar results $(7,8,9,10)$. The few studies focused on forestry-related certification have shown no effect on aggregate injury rates $(7,8)$. In certification studies in other occupations or industries, the requirement for youth to be trained and certified in the operation of tractors on public roads had no effect on the rate of tractor crashes in the agricultural industry (9) and a commercial driver-licensing program found no effect on traffic accidents (10). The results from this study suggest that training and, in particular, certification through the demonstration of safe-work practices may not be sufficient to reduce injury risk among an experienced workforce. This is consistent with a recent systematic review that found that training alone was not effective in improving health and safety at work (21). Of note, "grandfathering" or the practice of applying a different standard to those already in the industry when a new occupational health and safety intervention is implemented may reduce the effectiveness of these regulations. As there were too few new tree-faller trainees, we could not assess if the more extensive training they received would have been more effective in reducing injury risk.

It should be noted that in the current study and previous studies, certification programs do not appear to introduce harm and may very well prevent at-risk workers from entering the occupation either by self-selection (ie, do not choose to participate in certification) or by failing certification. Data was not available for fallers who failed the examination or opted out of certification in the current study. These individuals may have a higher baseline risk of injury and excluding them from the precertification analysis period could have attenuated any positive effect of certification on the tree-faller population. Despite the preceding methodological challenge, the current study offered improvements over previous evaluation studies.

Constructing the survival analysis using quarterly time periods facilitated the assessment of risk during follow-up while mitigating the effects of variability due to low injury counts, as well as minimizing some seasonal or temporal effects. Support for using quarterly periods as opposed to days, weeks, or months was based on obtaining reliable estimates of injury risk for a relatively small workforce. Aggregating injuries into
Table 2. Injury rate (number of injuries per 100 person years a) by certification status and study confounders

\begin{tabular}{|c|c|c|c|c|}
\hline & \multirow{2}{*}{$\begin{array}{c}\text { All } \\
\text { injuries }\end{array}$} & \multicolumn{3}{|c|}{ Injury rate } \\
\hline & & Acute & Strain & Serious \\
\hline Overall & 5.0 & 2.9 & 2.1 & 2.4 \\
\hline \multicolumn{5}{|c|}{$\begin{array}{l}\text { One year before certification } \\
\text { (3- month discrete periods) }\end{array}$} \\
\hline Period 1 & 4.3 & 2.6 & 1.7 & 1.7 \\
\hline Period 2 & 4.3 & 3.0 & 1.3 & 2.1 \\
\hline Period 3 & 4.7 & 3.0 & 1.7 & 1.6 \\
\hline Period 4 & 2.7 & 1.6 & 1.1 & 0.9 \\
\hline \multicolumn{5}{|c|}{$\begin{array}{l}\text { One year after certification } \\
\text { (3-month discrete periods) }\end{array}$} \\
\hline Period 5 & 6.0 & 3.1 & 2.9 & 2.7 \\
\hline Period 6 & 6.6 & 4.4 & 2.2 & 4.0 \\
\hline Period 7 & 6.9 & 2.9 & 4.0 & 3.5 \\
\hline Period 8 & 4.7 & 2.9 & 1.8 & 2.8 \\
\hline \multicolumn{5}{|l|}{ Age (years) } \\
\hline $15-24$ & 8.9 & 6.0 & 2.9 & 2.0 \\
\hline $25-34$ & 4.9 & 2.9 & 2.0 & 1.7 \\
\hline $35-44$ & 5.2 & 3.0 & 2.2 & 2.0 \\
\hline $45-54$ & 4.4 & 2.4 & 2.0 & 2.4 \\
\hline $55-64$ & 4.8 & 2.6 & 2.2 & 2.9 \\
\hline \multicolumn{5}{|l|}{ Faller type } \\
\hline Production & 5.4 & 3.0 & 2.4 & 2.6 \\
\hline Non-production & 1.2 & 1.2 & 0.0 & 0.2 \\
\hline \multicolumn{5}{|l|}{ Region } \\
\hline Coast & 8.8 & 5.0 & 3.8 & 4.2 \\
\hline Southern interior & 2.3 & 1.4 & 0.9 & 1.0 \\
\hline Northern interior & 0.8 & 0.5 & 0.3 & 0.6 \\
\hline \multicolumn{5}{|c|}{ Work experience (years) } \\
\hline $1-2$ & 6.0 & 3.1 & 2.9 & 2.2 \\
\hline $3-5$ & 3.4 & 2.2 & 1.4 & 1.3 \\
\hline $6-10$ & 5.0 & 3.3 & 1.7 & 2.4 \\
\hline $11-20$ & 5.3 & 2.6 & 2.7 & 2.0 \\
\hline$\geq 21$ & 5.4 & 3.0 & 2.4 & 3.5 \\
\hline \multicolumn{5}{|c|}{ Certificate grade level } \\
\hline 1 & 1.8 & 1.1 & 0.7 & 1.0 \\
\hline 2 & 4.2 & 3.0 & 1.2 & 2.1 \\
\hline 3 & 8.9 & 5.2 & 3.7 & 4.4 \\
\hline 4 & 12.2 & 6.0 & 6.2 & 5.6 \\
\hline 5 & 11.5 & 4.6 & 6.9 & 3.2 \\
\hline \multicolumn{5}{|c|}{ Industry unemployment rate (\%) } \\
\hline $0.0-5.9$ & 3.9 & 1.9 & 2.0 & 1.8 \\
\hline $6.0-8.9$ & 4.8 & 3.0 & 1.8 & 2.6 \\
\hline $9.0-11.9$ & 5.2 & 2.7 & 2.5 & 2.5 \\
\hline$\geq 12.0$ & 7.2 & 4.6 & 2.6 & 2.6 \\
\hline
\end{tabular}

${ }^{a}$ Assuming uniform time-at-risk through the two-year follow-up period.

discrete 3-month periods by injury date meant that the total number of injuries in a given time period was stable and reduced the variability in risk of injury to a point where trends could be observed and 95\% CI calculated. Other evaluation approaches, such as an interrupted time-series analysis, were not appropriate as the intervention was phased in throughout the study period with no defined "structural" break in the data. Further, we did not have individual-level data on hours worked for calculating injury rates, as this data is not collected as part of the tree-faller registry. This study assumes uniform work time-as-risk during the study periods, a reasonable assumption given the requirement for employment as a 
Table 3. Relative risk (RR) of a workers' compensation claim for acute, strain and serious injuries by certification status adjusted for confounders among experienced tree-fallers in British Columbia, 2003-2008. [Ref=reference value]

\begin{tabular}{|c|c|c|c|c|c|c|c|c|}
\hline & \multicolumn{2}{|c|}{ All injuries } & \multicolumn{2}{|c|}{ Acute injuries } & \multicolumn{2}{|c|}{ Strain injuries } & \multicolumn{2}{|c|}{ Serious injuries } \\
\hline & $\mathrm{RR}$ & $95 \% \mathrm{Cl}$ & $\mathrm{RR}$ & $95 \% \mathrm{Cl}$ & $\mathrm{RR}$ & $95 \% \mathrm{Cl}$ & $\mathrm{RR}$ & $95 \% \mathrm{Cl}$ \\
\hline \multicolumn{9}{|c|}{$\begin{array}{l}\text { One year before certification } \\
\text { (3-month discrete periods) }\end{array}$} \\
\hline Period 1 & Ref & & Ref & & Ref & & Ref & \\
\hline Period 2 & 1.01 & $0.62-1.64$ & 1.06 & $0.58-1.96$ & 0.92 & $0.42-2.02$ & 1.14 & $0.34-1.76$ \\
\hline Period 3 & 0.67 & $0.38-1.18$ & 0.59 & $0.28-1.24$ & 0.75 & $0.32-1.77$ & 0.77 & $0.18-1.24$ \\
\hline Period 4 & & & & & & & 0.47 & \\
\hline \multicolumn{9}{|c|}{$\begin{array}{l}\text { One year after certification } \\
\text { (3-month discrete periods) }\end{array}$} \\
\hline Period 5 & 1.45 & $0.91-2.32$ & 1.15 & $0.62-2.15$ & 1.91 & $0.95-3.84$ & 1.58 & $0.78-3.22$ \\
\hline Period 6 & 1.56 & $0.97-2.49$ & 1.62 & $0.89-2.92$ & 1.38 & $0.65-2.93$ & 2.04 & $1.02-4.05$ \\
\hline Period 7 & 1.79 & $1.13-2.85$ & 1.11 & $0.58-2.13$ & 2.77 & $1.40-5.48$ & 1.88 & $0.93-3.80$ \\
\hline Period 8 & 1.25 & $0.76-2.07$ & 1.11 & $0.58-2.14$ & 1.41 & $0.65-3.05$ & 1.64 & $0.80-3.39$ \\
\hline \multicolumn{9}{|l|}{ Age (years) } \\
\hline $15-24$ & 2.93 & $1.56-5.49$ & 3.44 & $1.54-7.68$ & 2.25 & $0.82-6.21$ & 1.16 & $0.32-4.23$ \\
\hline $25-34$ & 1.48 & $0.99-2.23$ & 1.47 & $0.85-2.54$ & 1.47 & $0.81-2.67$ & 1.73 & $0.96-3.11$ \\
\hline $35-44$ & 1.34 & $0.96-1.87$ & 1.44 & $0.92-2.2 .6$ & 1.20 & $0.74-1.94$ & 1.13 & $0.69-1.86$ \\
\hline $45-54$ & Ref & & Ref & & Ref & & Ref & \\
\hline $55-64$ & 1.16 & $0.75-1.81$ & 1.18 & $0.65-2.14$ & 1.10 & $0.57-2.12$ & 1.23 & $0.69-1.86$ \\
\hline \multicolumn{9}{|l|}{ Faller type } \\
\hline Non production & Ref & & Ref & & a & & Ref & \\
\hline Production & 2.09 & $0.92-4.76$ & 1.31 & $0.57-3 . .04$ & a & & 6.02 & $0.83-43.58$ \\
\hline \multicolumn{9}{|l|}{ Region } \\
\hline Northern interior & Ref & & Ref & & Ref & & Ref & \\
\hline Southern interior & 2.43 & $1.22-4.84$ & 2.64 & $1.09-6.35$ & 2.20 & $0.73-6.62$ & 1.46 & $0.61-3.50$ \\
\hline Coast & 5.48 & $2.80-10.73$ & 5.40 & $2.28-12.80$ & 5.82 & $2.00-16.88$ & 4.21 & $1.84-9.64$ \\
\hline \multicolumn{9}{|c|}{ Work experience (years) } \\
\hline $1-2$ & 1.61 & $0.97-2.67$ & 1.27 & $0.64-2.50$ & 2.19 & $1.00-4.79$ & 1.76 & $0.77-4.01$ \\
\hline $3-5$ & Ref & & Ref & & Ref & & Ref & \\
\hline $6-10$ & 1.43 & $0.94-2.19$ & 1.46 & $0.86-2.49$ & 1.39 & $0.69-2.83$ & 1.78 & $0.93-3.42$ \\
\hline $11-20$ & 1.33 & $0.87-2.05$ & 1.12 & $0.64-1.96$ & 1.83 & $0.93-3.61$ & 1.32 & $0.67-2.62$ \\
\hline$\geq 21$ & 1.35 & $0.82-2.20$ & 1.24 & $0.65-2.34$ & 1.55 & $0.71-3.38$ & 2.15 & $1.03-4.50$ \\
\hline \multicolumn{9}{|c|}{ Certificate grade level } \\
\hline 1 & Ref & & Ref & & Ref & & Ref & \\
\hline 2 & 1.24 & $0.83-1.84$ & 1.60 & $0.98-2.63$ & 0.86 & $0.44-1.69$ & 1.04 & $0.59-1.83$ \\
\hline 3 & 2.02 & $1.33-3.07$ & 2.14 & $1.25-2.63$ & 2.02 & $1.05-3.88$ & 1.71 & $0.95-3.06$ \\
\hline 4 & 2.18 & $1.44-3.31$ & 1.62 & $0.92-2.86$ & 3.04 & $1.63-5.67$ & 1.51 & $0.83-2.75$ \\
\hline 5 & 2.15 & $1.24-3.71$ & 1.48 & $0.66-3.32$ & 3.14 & $1.45-6.80$ & 1.07 & $0.44-2.62$ \\
\hline \multicolumn{9}{|l|}{ Previous claim } \\
\hline No & Ref & & Ref & & Ref & & Ref & \\
\hline Yes & 2.87 & $2.18-3.76$ & 3.30 & $2.29-4.75$ & 2.43 & $1.61-3.67$ & 2.99 & $2.01-4.44$ \\
\hline \multicolumn{9}{|c|}{ Unemployment industry rate (\%) } \\
\hline $0.0-5.9$ & Ref & & Ref & & Ref & & Ref & \\
\hline $6.0-8.9$ & 1.13 & $0.80-1.61$ & 1.48 & $0.90-2.46$ & 0.81 & $0.49-1.35$ & 1.26 & $0.76-2.10$ \\
\hline $9.0-11.9$ & 1.16 & $0.78-1.71$ & 1.23 & $0.70-2.16$ & 1.11 & $0.65-1.90$ & 1.11 & $0.62-1.97$ \\
\hline$\geq 12.0$ & 1.77 & $1.11-2.83$ & 2.25 & $1.19-4.24$ & 1.47 & $0.74-2.94$ & 1.42 & $0.67-1.24$ \\
\hline
\end{tabular}

a Insufficient number of injuries for the "not-production" faller type to include production type as a confound in the strain injury model.

faller to challenge the certification exam and the global demands for forestry resources during a period of low unemployment.

Following the certification exam, a greater propensity to report injuries following the introduction of a safety intervention may have led to an increase in the incidence of injury occurrence in comparison to the pre-certification time period (19). However, the increase in risk for serious injuries during the post certification periods suggests that increased reporting may not be the only contributing factor. Serious injuries are those that require either extensive healthcare and/or significant time off work and are not likely to be sensitive to reporting biases.

The observed decrease in injury risk pre-certification and increase post-certification (albeit not statistically significant) may be partly attributable to the assumption that all tree-fallers were working fulltime felling trees during all of the pre- and post-certification follow-up periods. It is possible that certification represents a transition from a period of unemployment to employment in the occupation. In other words, it may be that manual tree-fallers obtained certification during periods 
of unemployment or reduced employment, representing periods of reduced exposure and injury risk. An alternate explanation is that tree-fallers sought certification upon returning from a seasonal period of employment layoff. However, certification exam dates were equally distributed throughout a calendar year suggesting no association between season and certification. Nevertheless, in the absence of detailed employment data on work hours in the tree-faller registry records, the possibility persists that post certification follow-up periods represent periods of increased employment and therefore increased exposure to injury risk. To minimize this potential bias, the risk of injury associated with certification was investigated for only one year prior to and one year after the certification date with the justification that experienced tree-fallers required a minimum of two years of work experience prior to challenging the certification examination and that certification was required in order to maintain employment in the industry.

The lack of a significant effect of certification on the reduction of work injury risk in this study may be because experienced tree-fallers challenged the certification examination without participating in the structured classroom, field, and on-the job training (22-24). Although experienced fallers are aware of best practices and can demonstrate these in a testing environment, on the job exposure to concurrent and dynamic work environment hazards may require a more complex application of these practices than the testing process can assess. Certification may not negate the risks associated with tree-falling when safe work practices have to be applied or adjusted in an environment characterized by highly variable terrain, weather and trees (25). Alternative or complementary safety interventions may be needed to improve work health outcomes in concert with certification in safe work practices. These include engineered safety controls, improvement in organizational policies and management practices or improvement in working conditions. For example, the use of hydraulic wedges that are remotely operated removes fallers from the immediate area of a falling tree $(26,27)$. Improvements in work conditions such as limiting the number of hours worked per day, including travel time to a worksite, could reduce faller fatigue. Reducing fatigue is associated with improved recognition of potentially hazardous situations and improved decision-making to reduce exposure to these hazards $(28,29)$.

It is recommended that a future study be conducted once more new tree-faller trainees obtain certification. This would permit the investigation of the full effect of certification on injury risk among those first entering the occupation. Designing a prospective follow-up study to assess tree-faller injury risk would permit the collection of more accurate work time-at-risk data not available in the retrospective administrative data used in the present study. A prospective study design would also permit the inclusion of workers not captured in the registry such as fallers who exited the industry prior to certification or those who were not able to obtain certification.

The results suggest that certification based on the demonstration of safe work practices did not reduce the risk of work injury among experienced manual tree-fallers who challenged the certification exam. Additional or complementary interventions such as those that focus on behavioral and organizational factors may be required to reduce work injury risk among experienced tree-fallers who work in highly variable and dangerous work environments.

\section{Acknowledgments}

This research was supported in part by funding from WorkSafeBC (Workers' Compensation Board of British Columbia) and the Workers' Compensation Board of Nova Scotia, through the Focus ON TOMORROw program. M Koehoorn was supported in part by a Michael Smith Foundation for Health Research Senior Scholar Award. C McLeod was supported in part by a Social Sciences and Humanities Research Council Postdoctoral Fellowship and receives partial salary support from WorkSafeBC. D Sarkany was supported by a WorkSafeBC Research Trainee Award.

\section{References:}

1. West R, Shkrum M, Young J. Commercial logging fatalities in Ontario, 1986-1991. Am J Forensic Med Pathol. 1996;17(4):299-304. http://dx.doi.org/10.1097/00000433199612000-00004.

2. Lindroos O, Burström L. Accident rates and types among selfemployed private forest owners. Accid Anal Prev. Elsevier Ltd; 2010 Nov;42(6):1729-35.

3. Brodie L, Ibrahim J. Fatal injury in tree felling and related activities, Victoria, Australia, 1992-2007. Inj Prev. 2010;16(1):53-6. http://dx.doi.org/10.1136/ip.2009.021683.

4. Wang J, Bell J, Grushecky S. Logging injuries for a 10-year period in Jilin province of the People's Republic of China. J Saf Res. 2003;34(3):273-9. http://dx.doi.org/10.1016/S00224375(03)00024-0.

5. Bentley T, Parker R, Ashby L. Understanding felling safety in the New Zealand forest industry. Appl Erg. 2005;36(2):16575. http://dx.doi.org/10.1016/j.apergo.2004.10.009.

6. Scott D. A study of logger fatalities from 1992-2000. Inj Prev. 2004;10(4):239-43. http://dx.doi.org/10.1136/ ip.2003.004663.

7. Mujuru P, Helmkamp J, Mutambudzi M, Hu M, Bell J. Evaluating the impact of an intervention to reduce injuries 
among loggers in West Virginia, 1999-2007. J Agric Saf Heal. 2009;15(1):75-88. http://dx.doi.org/10.13031/2013.25416.

8. Bell J, Grushecky S. Evaluating the effectiveness of a logger safety training program. J Saf Res. 2006;37(1):53-61. http:// dx.doi.org/10.1016/j.jsr.2005.10.019.

9. Hagge R, Romanowicz P. Evaluation of California's Commercial Driver License Program. Accid Anal Prev. 1996;28(5):547-59. http://dx.doi.org/10.1016/00014575(96)00013-9.

10. McGwin G, Whatley J, Metzger J, Valent F, Barbone F, Rue L. The effect of state motorcycle licensing laws on motorcycle driver mortality rates. J Trauma, Inj Infect Crit Care. 2005;56:415-9. http://dx.doi.org/10.1097/01. TA.0000044625.16783.A9.

11. Robson LS, Stephenson CM, Schulte PA, Amick BCI, Irvin EL, Eggerth DE, et al. A systematic review of the effectiveness of occupational health and safety training. Scand J Work Environ Health. 2012 May 1;38(3):193-208. http://dx.doi. $\operatorname{org} / 10.5271 /$ sjweh.3259.

12. Young T, Guess F. A statistical analysis of tree-harvesting worker safety. Internaional J Reliab Appl. 2002;3(2):61-79.

13. Smith S, de Hoop C, Marx B, Pine J. Logging injuries in Lousian: nature, trends, and rehabilitation considerations. Work. 1999;12:261-73.

14. WorkSafeBC. WorkSafeBC Claims and Firm Level Files. V2. Population Data BC; 2011. Linked Dataset. Available from: http://www.popdata.bc.ca/data

15. Population Data BC. The data access process. Vancouver, BC: University of British Columbia; 2009. Available from: http:// www.popdata.bc.ca/dataaccess/process

16. Fan J, McLeod CB, Koehoorn M. Descriptive Epidemiology of Serious Work-Related Injuries in British Columbia, Canada. PLoS One. 2012 Jun 19;7(6):e38750. http://dx.doi. org/10.1371/journal.pone.0038750.

17. Canadian Standards Association. CSA Z795-1996 Coding of Work Injury or Disease Information. R2001 ed. Toronto, Ontario: Canadian Standards Assocation; 1996. p. 300.

18. WorkSafeBC. WorkSafeBC Statistics 2009. Richmond, BC; 2010.

19. Singer J, Willet J. Applied Longitudinal Data Analysis. First Edit. New York, NY: Oxford University Press; 2003. http:// dx.doi.org/10.1093/acprof:oso/9780195152968.001.0001.
20. McLeod C, Lavis J, MacNab Y, Hertzman C. Unemployment and mortality: A comparative study of Germany and the United States. Am J Public Health. 2012;102(8):1542. http://dx.doi. org/10.2105/AJPH.2011.300475.

21. Robson L, Stephenson C, Schulte P, Amick B, Chan S, Bielecky A, Wang A, Heidotting T, Irvin E, Eggerth D, Peters R, Clarke J, Cullen K, Boldt L, Rotunda C, Grubb P. A systematic review of the effectiveness of training \& education for the protection of workers. Toronto: Institute for Work \& Health, 2010; Cincinnati, OH: National Institute for Occupational Safety and Health.

22. Burke M, Sarpy S, Smith-Crowe K, Chan-Serafin S, Salvador $\mathrm{R}$, Islam $\mathrm{G}$. Relative effectiveness of worker safety and health training methods. Am J Public Heal. 2006;96(2):315-24. http://dx.doi.org/10.2105/AJPH.2004.059840.

23. Rasmussen K, Carstensen O, Lauritsen J, Glasscock D, Hansen O, Jensen U. Prevention of farm injuries in Denmark. Scand J Work Env Heal. 2003;29(4):288-96. http://dx.doi. org/10.5271/sjweh.733.

24. Robson LS, Clarke JA, Cullen K, Bielecky A, Severin C, Bigelow PL, et al. The effectiveness of occupational health and safety management system interventions: A systematic review. Saf Sci. 2007 Mar;45(3):329-53. http://dx.doi.org/10.1016/j. ssci.2006.07.003.

25. Colman J, Kahle H, Henriqson E. Is performance variability necessary or counterproductive for safely felling trees in the coastal region of British Columbia? J Hum Perfomance Extrem Environ. 2013;11(1):1-6.

26. Lyons K, Florian N. Optimizing a novel method for manually falling trees. For Chron. 2011;87(4):537-41. http://dx.doi. org/10.5558/tfc2011-052.

27. Lyons K, Ewart J. The Wood duck; a new tree-falling tool. West J Appl For. 2012;27(3):137-42. http://dx.doi. org/10.5849/wjaf.11-026.

28. WorkSafeBC. A report and action plan to eliminate deaths and serious injuries in British Columbia's forests: Final Report of the Forest Safety Task Force. Richmond, BC: WorkSafeBC; 2004.

29. Western Fallers' Association. Western fallers' association report - A view from the field: Report on contributing factors to faller accidents in British Columbia. Vancouver, BC: WorkSafeBC; 2005.

Received for publication: 5 September 2014 